\title{
Conselhos de fiscalização profissional e proteção da sociedade
}

Eduardo Neubarth Trindade ${ }^{1}$, Márcia Vaz ${ }^{1}$, Juliano Lauer ${ }^{1}$, Vanessa Schmidt Bortolini ${ }^{1}$, Manoel Roberto Maciel Trindade ${ }^{1}$

1. Conselho Regional de Medicina do Estado do Rio Grande do Sul, Porto Alegre/RS, Brasil.

\section{Resumo}

A República Federativa do Brasil, ao reconhecer o valor da liberdade do exercício profissional e o dever de proteger a sociedade, delegou aos conselhos profissionais atividades típicas de poder de fiscalização ética e técnica de pessoas que exercem determinadas profissões. A essa função típica de Estado são somados ainda o exercício de um serviço público e o papel de zelar pelo bom prestígio da profissão. Os conselhos de fiscalização profissional cumprem essas funções de forma legítima, democrática, eficaz e com incontestável valor social. Para que essas entidades continuem exercendo suas missões institucionais, é necessário defender seu reconhecimento como pessoas jurídicas de direito público, detentoras do poder de fiscalização.

Palavras-chave: Constituição e estatutos. Ética profissional. Administração pública.

\section{Resumen}

\section{Consejos de supervisión profesional y protección de la sociedad}

La República Federativa de Brasil, reconociendo el valor de la libertad de ejercicio profesional y el deber de proteger a la sociedad, delegó en los consejos profesionales actividades típicas de poder de supervisión ética y técnica de las personas que ejercen ciertas profesiones. A esta función típica del Estado se añaden el ejercicio de un servicio público y el papel de velar por el buen prestigio de la profesión. Los consejos profesionales de supervisión desempeñan estas funciones de manera legítima, democrática, efectiva y con un valor social innegable. Para que estas entidades puedan continuar ejerciendo sus misiones institucionales, es necesario defender su reconocimiento como personas jurídicas de Derecho Público, titulares de la facultad de supervisión.

Palabras clave: Constitución y estatutos. Ética profesional. Administración pública.

\begin{abstract}
Professional supervisory boards and protection of society

The Federative Republic of Brazil, in recognizing the value of freedom of professional practice and the duty to protect society, delegated to professional councils activities typical of ethical and technical supervision of people who exercise certain professions. To this typical function of the State are also added the exercise of a public service and the role of ensuring the good prestige of the profession. Professional supervisory boards fulfill these functions in a legitimate, democratic, effective way and with undeniable social value. For these entities to continue exercising their institutional missions, it is necessary to defend their recognition as legal entities of public law, holders of supervisory power. Keywords: Constitution and bylaws. Ethics, professional. Public administration.
\end{abstract}


A palavra "profissão", do latim professio, significava originalmente o ato ou efeito de professar $^{1}$, relacionando-se a crenças, valores ou compromissos. Somente a partir do século XVIII o termo passou a ter o sentido atual, ou seja, o ato de exercer um ofício, uma ciência ou uma arte ${ }^{2}$.

As profissões, tal como conhecidas hoje, resultam de um processo histórico relativo a formas de organização do trabalho e necessidades sociais ${ }^{3}$. O desenvolvimento das forças produtivas e a transformação da sociedade resultaram na criação de diversas profissões, com conhecimentos, teorias e práticas próprias. Essas profissões foram se tornando cada vez mais especializadas, a fim de atender novas demandas.

Enquanto essência das relações de trabalho e da livre iniciativa, as profissões são necessárias para o desenvolvimento de uma sociedade, não somente sob o aspecto econômico, mas também da promoção do bem-estar e da dignidade dos indivíduos. Tendo isso em vista, a Constituição brasileira, já em seu primeiro artigo, aponta o valor social do trabaIho e da livre iniciativa como um dos fundamentos da república. E o artigo $5^{\circ}$, inciso XIII, estabelece que é livre o exercício de qualquer trabalho, ofício ou profissão, mas resguardando a possibilidade de a lei estabelecer as qualificações profissionais necessárias para que se exerça tal direito ${ }^{4}$.

A ressalva constitucional tem como razão o fato de que as profissões têm repercussão social, e é necessário proteger a coletividade contra pessoas mal-intencionadas que não preencham requisitos mínimos para o exercício profissional em determinadas áreas. É nesse contexto que os conselhos de fiscalização profissional se destacam como entidades que regulamentam, normatizam e fiscalizam o exercício da profissão em prol da sociedade.

\section{Conselhos de fiscalização profissional}

\section{e sua natureza}

Embora a Constituição Federal tenha outorgado à União a competência para legislar e fiscalizar o exercício profissional, em determinadas profissões tal função foi delegada, por meio de leis específicas, aos denominados "conselhos de fiscalização profissional" ${ }^{5}$. Esses conselhos são geridos por profissionais da área que, eleitos por seus pares, cumprem mandatos ${ }^{6}$. Seus dirigentes não são remunerados, exercendo funções honoríficas.
Essas entidades fiscalizatórias recebem diversas denominações na doutrina, dentre as quais pode-se citar: "autarquias para-administrativas", "corporações autárquicas", "corporações profissionais", "instituições corporativas" e "autarquias corporativas". Assim, apesar de nem todas as leis instituidoras dos conselhos de fiscalização profissional preverem expressamente a natureza autárquica dessas entidades, a doutrina e a jurisprudência reconhecem tal natureza. Trata-se, no entanto, de autarquia peculiar, diferenciada, que não integra a administração pública federal, nem se enquadra nos preceitos do Decreto-Lei 200/19677.

Como entidades não integrantes da administração pública, os conselhos de fiscalização profissional têm autonomia financeira e administrativa, não recebem subvenções ou repasses financeiros da União e tampouco estão submetidos a supervisão ministerial. Para fazer frente a suas missões institucionais, os conselhos detêm a prerrogativa de arrecadar tributos de seus inscritos, dentre os quais as contribuições de interesse de categoria profissional (as "anuidades") e outras taxas, conforme estabelecido em lei federal.

Dada sua natureza autárquica, os conselhos têm personalidade jurídica de direito público e se submetem aos ditames constitucionais. Dentre esses ditames, destacam-se a observância dos princípios da legalidade estrita (só se pode fazer o que a legislação permite), a impessoalidade, a moralidade administrativa, a publicidade e a eficiência. Os conselhos de fiscalização profissional, portanto, estão submetidos ao sistema de concurso público para arregimentação de pessoal e obrigados à realização de processo licitatório para adquirir bens e serviços. Seus atos, ademais, são controlados e fiscalizados pelo Tribunal de Contas da União, e sua atuação deve ter finalidade pública.

\section{Funções dos conselhos de fiscalização profissional}

Embora o papel fundamental dos conselhos de fiscalização profissional seja regulamentar e fiscalizar a ética profissional, é preciso destacar que essas entidades cumprem outras funções de interesse social. Conforme estabelece o arcabouço legal, determinadas profissões só podem ser exercidas após registro em conselho de fiscalização 
profissional, quando são aferidas as condições e habilitação do profissional. Pode-se dizer, portanto, que essas entidades têm papel cartorial, já que certificam a restrição do exercício profissional àqueles que demonstram habilitação técnica mínima.

Para desempenhar suas atribuições de fiscalização e proteger a coletividade, os conselhos apuram e julgam, com exclusividade, a responsabilidade administrativa de seus inscritos, verificando o comportamento ético e a capacidade técnica do profissional e aplicando as penalidades estabelecidas em lei quando necessário. Um exemplo é a norma de criação dos conselhos de medicina, que atribui a essas entidades a função de fiscalizar o exercício da profissão de médico e conhecer, apreciar e decidir os assuntos atinentes à ética profissional, impondo as penalidades que couberem (art. 15, alíneas " $c$ " e "d") ${ }^{7}$. Logo, ao processar e julgar seus inscritos, os conselhos cumprem também função judicante, assegurando que o julgamento observe o devido processo legal, com garantia do contraditório e ampla defesa.

Os conselhos também cumprem o relevante papel de coibir que leigos exerçam ilegalmente a profissão regulamentada. São diversas as medidas administrativas e judiciais que essas entidades adotam para denunciar às autoridades policiais e ao Ministério Público o crime de exercício ilegal da profissão e ilícitos contra consumidores, como publicidade enganosa. A título de exemplo, pode-se mencionar parcerias entre os conselhos de medicina e o Ministério Público que visam aprimorar os mecanismos de representação criminal contra charlatões e pessoas mal-intencionadas ${ }^{8}$.

Outra função dos conselhos de fiscalização profissional é representar os interesses da categoria profissional. Embora não se confundam com sindicatos ou associações, os conselhos buscam proteger as prerrogativas dos seus inscritos, impetrando ações judiciais contra medidas que tolham o livre e digno exercício da profissão. Essas ações podem contestar inclusive o poder público, sobretudo quando atos governamentais e normas infralegais permitam que pessoas não capacitadas e qualificadas tecnicamente atuem sem amparo legal, em atividades privativas dos profissionais, colocando em risco a sociedade.

Um exemplo recente de representação dos interesses profissionais e defesa da sociedade são as manifestações dos conselhos federal e regionais de medicina contra a permissão do Governo Federal à abertura de novas faculdades na área sem a devida avaliação da qualidade do ensino ${ }^{9}$. Esses conselhos também têm se colocado contra: a flexibilização do processo de Revalidação de Diplomas Médicos Expedidos por Instituição de Educação Superior Estrangeira (Revalida) ${ }^{10}$; a abertura de planos de saúde populares, com coberturas limitadas a consultas ambulatoriais e a exames subsidiários de menor complexidade, excluindo parte da população que mais necessita de atendimento médico, como doentes crônicos e idosos ${ }^{11}$; e a proliferação de tratamentos estéticos invasivos feitos por pessoas que não detêm os conhecimentos técnicos necessários para atuar em caso de intercorrências causadas por esses procedimentos ${ }^{12}$.

Os conselhos de fiscalização profissional também são com frequência instados a se manifestar tecnicamente em deliberações de órgãos da estrutura estatal, mormente sobre políticas públicas do Poder Executivo das três esferas da Federação (municipal, estadual e federal), projetos de lei em tramitação no Congresso Nacional e ações judiciais, como amicus curiae.

Todas essas funções dos conselhos de fiscalização profissional representam sua finalidade de proteção à sociedade, que é feita de forma legítima, democrática, eficaz e com incontestável valor social.

"Legítima", pois somente entidades de natureza pública - como os conselhos profissionais, que são autarquias federais - podem exercer a fiscalização profissional, por delegação da União, o que Ihes permite aplicar sanções a profissionais que cometem infrações deontológicas, apuradas em processos administrativos com garantia do contraditório e ampla defesa.

"Democrática" porque os conselhos são dirigidos por representantes eleitos pelos próprios profissionais e que detêm conhecimento técnico para o fiel exercício das funções normativa e fiscalizatória. Isso possibilita a conciliação e o julgamento técnico por profissionais da mesma área, isto é, os pares são regulados, fiscalizados e julgados por seus próprios pares, que têm conhecimento e maior capacidade de empatia.

"Eficaz", pois o registro profissional garante qualidade, confiança e credibilidade, uma vez que por meio desse procedimento se afere o cumprimento dos requisitos legais e técnicos para o exercício da profissão. Por fim, os conselhos têm 
também incontestável papel social, vez que protegem a sociedade de maus profissionais, que não exercem suas atividades de forma correta, ou atuam de forma ilegal, sem a devida habilitação ${ }^{13}$. Essa função é importante sobretudo nas profissões ligadas à vida, à saúde, ao bem-estar, à segurança e à liberdade da população.

Os conselhos profissionais também são espaços para debater grandes temas, muitas vezes trazendo à tona novas tecnologias, revisando conhecimentos, aprimorando a profissão e discutindo aspectos éticos e disciplinares que envolvem a prática profissional. Dessa forma, essas entidades protegem a sociedade e defendem a saúde, a segurança e a liberdade dos cidadãos.

\section{Considerações finais}

Os conselhos de fiscalização profissional têm papel fundamental na proteção à saúde, à vida, ao bem-estar, à segurança e à liberdade da população, e só podem cumprir essas funções a partir de seu reconhecimento como pessoas jurídicas de direito público. Com efeito, para pleno exercício de suas funções, os atos emanados dos conselhos de fiscalização profissional devem possuir discricionariedade, coercibilidade e autoexecutoriedade (atributos típicos dos atos dos agentes públicos), a fim de que se imponham restrições aos direitos individuais dos profissionais em favor dos interesses maiores da coletividade.

Tal observação é importante e deve estar presente nos debates da sociedade, sobretudo quando iniciativas legislativas buscam transformar os conselhos de fiscalização profissional em pessoas jurídicas de natureza privada, retirando a obrigatoriedade do registro profissional e o poder de aplicar sanções. Portanto, cabe à população e sobretudo aos profissionais entender e defender o papel fundamental dos conselhos de fiscalização profissional na defesa dos interesses coletivos.

\section{Referências}

1. Ferreira $\mathrm{ABH}$. Dicionário Aurélio da Língua Portuguesa. $5^{\mathrm{a}}$ ed. Curitiba: Positivo; 2010.

2. Breda Z. Qual é o papel dos conselhos profissionais? [Internet]. Brasília: Conselho Federal de Contabilidade; 2019 [acesso 14 ago 2020]. Disponível: https://bit.ly/36ZwG5N

3. Kroeff MS, Mattos MCC, Matos JC, Spudeit DFA. Sociologia das profissões e o profissional da informação. Comun Inf [Internet]. 2017 [acesso 22 set 2020];20(3):18-33. DOI: 10.5216/ci.v20i3.41325

4. Brasil. Constituição da República Federativa do Brasil [Internet]. Brasília: Senado Federal; 2016 [acesso 26 jul 2020]. Disponível: https://bit.ly/2YjZyT0

5. Medauar O. Direito administrativo moderno. $21^{\mathrm{a}}$ ed. Belo Horizonte: Fórum, 2018.

6. Gamba LH. Aspectos materiais da inscrição nos conselhos de fiscalização profissional. In: Freitas VP, organizador. Conselhos de fiscalização profissional: doutrina e jurisprudência. São Paulo: Revista dos Tribunais; 2013. p. 165-249.

7. Brasil. Lei $n^{\circ} 3.268$, de 30 de setembro de 1957. Dispõe sobre os Conselhos de Medicina, e dá outras providências. Diário Oficial da União [Internet]. Brasília, 1 out 1957 [acesso 22 set 2020]. Disponível: https://bit.ly/2TGV3Cg

8. Conselho Regional de Medicina do Estado do Rio Grande do Sul. Cremers cria canal exclusivo para denúncias de exercício ilegal da medicina [Internet]. 2019 [acesso 22 set 2020]. Disponível: https://bit.ly/3zx8XGa

9. Conselho Federal de Medicina. Abertura indiscriminada de escolas médicas põe em risco saúde da população [Internet]. 2011 [acesso 22 set 2020]. Disponível: https://bit.ly/3D8EFMK

10. Conselho Federal de Medicina. CFM reitera defesa do Revalida e se posiciona contra nova tentativa de flexibilização [Internet]. 2020 [acesso 22 set 2020]. Disponível: https://bit.ly/3sxcr9l

11. Conselho Federal de Medicina. CFM reitera críticas à criação de planos populares de saúde [Internet]. 2017 [acesso 22 set 2020]. Disponível: https://bit.ly/3AS7haV 
12. Conselho Federal de Medicina. Médicos alertam população para riscos em procedimentos estéticos feitos com profissionais não habilitados [Internet]. 2019 [acesso 22 set 2020]. Disponível: https://bit.ly/3xYmLs0

13. Rezende, MTM. O papel social dos conselhos profissionais na área da saúde. Rev Soc Bras Fonoaudiol [Internet]. 2007 [acesso 22 set 2020];12(1):8-10. DOI: 10.1590/S1516-80342007000100002

Eduardo Neubarth Trindade - Doutor - entrindade@hcpa.edu.br

(D) 0000-0002-0491-0736

Márcia Vaz - Doutora - marvaz961@gmail.com

(D) 0000-0003-3466-9653

Juliano Lauer - Especialista - julianolauer@hotmail.com

(D) 0000-0002-0591-2952

Vanessa Schmidt Bortolini - Especialista - vsbortolini@gmail.com

(iD) $0000-0002-3200-4845$

Manoel Roberto Maciel Trindade - Doutor - manoelrmtr@gmail.com

(ID) 0000-0001-7809-82964

Correspondência

Eduardo Neubarth Trindade - Av. Princesa Isabel, 921, Santana CEP 90620-001.

Porto Alegre/RS, Brasil.

Participação dos autores

Todos os autores contribuíram para a elaboração do artigo.

Recebido: 11.5.2021

Revisado: 29.6 .2021

Aprovado: 22.7 .2021 